\title{
Research on Structural and Management Optimization of Chinese Sport Industry based on Multi-factor Analysis and Hierarchy Model
}

\author{
Lina Zhu ${ }^{1, a^{*}}$, Yingwei Zhao ${ }^{1, a}$ \\ ${ }^{1}$ Qingdao University of Science \& Technology, Qingdao 261000, China \\ azhulina661@126.com
}

Keywords: Structural Optimization; Sport Industry Management; Multi-factor Analysis; Hierarchy Model; Financial Benefit.

\begin{abstract}
With the bursting development of sport science, the concept and performance of technology policy of sports industry in our country has carried on the preliminary discussion. Research suggests that the sports industry technology policy is to control the floorboard of the sports industry technology development policies. Sports industry technology policy including: sports industry technical standards, the sports industry technology development policy, the sports industry technology achievements transformation policy sports industry, sports industry intellectual property policy and technology import policy. We conduct research on structural and management optimization of Chinese sport industry based on multi-factor analysis and hierarchy model in this paper. The proposed model could in some degree help us modify our current management pattern and enhance the efficiency of management. In the final part, we give our prospect and future research schedule.
\end{abstract}

\section{General Introduction}

Economic development is inevitably accompanied by transformation and upgrading of industrial structure, a new economic development with the new industrial structure. As a sunrise industry, sports industry has made great progress in our country, but also faces the challenge of sustainable development. In order to realize the sustainable development of sports industry, the need to further optimize the industrial structure is urgently bursting. As a real sunrise industry, sports industry by physical and mental. Sports industry as a component part of national economy is undertaking the role which will pay attention to market efficiency and economic benefits [1-3]. But different from other industries, its characteristic is to improve the quality of the residents, the development of social production, achieve comprehensive development of personal and national. Work in the 2010 national sports meeting, state general administration of sports bureau chief put forward "in the field of sports industry, the comprehensive building, focusing on the sports service industry category is complete, reasonable structure, sports industry with Chinese characteristics and international competitiveness [4-6]. On March 19, 2010 and issued by the general office of the state council about speed up the development of sports industry guidance, to speed up the development of sports industry, optimizing the structure of sports industry, puts forward the guiding opinions [7]. These policies and opinions, suggests that the sports industry has stepped into a new stage of development, the sports industry structure adjustment is imperative [8].

Since the reform and open policy, our country sports industry have issued a series of policy to adapt to the establishment and development of the socialist market economy system, these policies adapted to the general need of the development of sports industry in China, promoted the development of sports industry. With the socialist market economic system gradually, and the progress of sports industrialization in our country, "micro" sports industry policy of "absence" phenomenon is increasingly common [9]. Because of the lack of relatively specific, actionable "micro" sports industry policy guidance, has affected the system, comprehensive, in-depth development of sports industry in our country. Sport industry technology policy is part of the sports industry policy, the current academic 
circles about the sports industry technology policy research has not yet been reported. Chinese scholars generally believed that industrial policy is the government in order to achieve certain economic and social goals and the formation and development of industry of the various policy interventions combined [10]. As a basic component of a country or region's economic policy, industrial policy is an indispensable basic element in the operation of market economy, the development of a country or region industry plays a very important role in regulating direction. At present, our country sports industry is in the industry to form and initial growth stage, there are caused by insufficient sports market mechanisms of market failure.

To solve the challenges with modern methodology, in this paper we undertake theoretical analysis on the issue of structural and management optimization of Chinese sport industry based on multi-factor analysis and hierarchy model. The detailed description of our proposed methodology is discussed more in-depth in the following sections.

\section{Principles of Chinese Sport Industry and Management}

The Definition of Sports Industry Structure. According to the research of the industry economics, the industrial structure is divided into three levels: level 1 is the national economy between primary industry, secondary industry and tertiary industry structure; Level 2 is three big national economy sectors between the internal compositions of industry structure; the third level is a structure between each industry in the industry. Sports industry structure should be subordinate to the third level, between each sector in the sports industry structure. Sports related research, the industrial structure can be defined as the ratio between the number of each industry and sports industry relationship, is the combination of each industry in the sports industry. The ratio between the amount of each industry to sports industry. Ratio between the number of each industry to sports industry refers to the sports industry in the allocation of resources, each industry output, employment, etc, the number and proportion of relations, represents the sub industries constitute the basic status and role in industry. Each industry is the relationship between sports industry refers to the sports industry sector, interaction and mutual restriction relationship between each industry closely relationship between the degree of important symbol is the level of intermediate product with each other. It is generally believed that produces a specific product or provides the specified services technology is the industry technology. Therefore, the production technology of systemization is the industry technology. Production technique to form the industrial technology, and produce products on the definition of sports industry, this paper USES the academic circles in recent years, the general understanding of concepts and classification of sports industry, sports industry will be considered including sports products of the production and business activities of collection, the sports industry is to satisfy people's needs and is engaged in the production and business activities of sports products.

People usually interpret industrial technology policy for technological development policies, namely industrial technology development direction, target and key technology choice, in fact the content of industrial technology policy is very extensive. It goes without saying that the basic content of sports industry technology policy need to refer to the basic content of the industrial technology policy. The current studies of industrial technology policy of specific content there aren't many research results, and the interpretation of the existing results relatively fuzzy, only the purpose of the industrial technology policy are given, such as some scholars pointed out that the main content of industrial technology policy includes two aspects, one is in order to realize the rationalization of industrial structure and technology policy; Secondly, in order to promote technological progress and technology policy.

Chinese Sport Industry and Management. In 2006 2008, the state general administration of sports, the national bureau of statistics, and the national development and reform commission three departments jointly conducted first sports industry statistics. During the sports industry has developed 
rapidly in our country, has successfully held the Beijing Olympic Games has the world influence, such as sporting events. Therefore, the development of sports industry structure in this period has representative significance. In 2006 2008 national sports and related industry is developing rapidly, realize the added value of 380.309 billion yuan, the average annual growth of $19.4 \%$, calculated on the basis of the comparable price significantly more than the GDP growth rate. 2008 national sports and related industry to realize the added value of 1, 55.497 billion yuan, accounting for $0.52 \%$ of GDP, employment of 3.1709 million people. Management of sports organizations achieve added value increased from 7.48 billion yuan to 7.48 billion yuan, an average annual growth of $25.37 \%$; To realize the added value of the sports fitness leisure industry increased from 4.698 billion yuan to 7.449 billion yuan, the annual average growth rate degree is $25.92 \%$; The added value of sports venues management implementation increased from 1.824 billion yuan to 3 billion yuan, the average annual growth rate of $28.24 \%$; The added value of sports brokerage industry achieve increased from 202 million yuan to 446 million yuan, the annual average growth rate of $48.59 \%$; The added value of implementation by the sports training industry 464 million yuan to 1.348 billion yuan, the annual average growth rate of $70.45 \%$; The added value of the national sports lottery achieve increased from 2.147 billion yuan to 3.527 billion yuan, the annual growth rate of $28.17 \%$. The evidence proves the urgent need of management for sport industry.

\section{Multi-factor Analysis and Hierarchy Model for Sport Management}

The Structure of Hierarchy Model. In the figure 1, we should the basic structure of hierarchy model. We could conclude from the flowchart that: In fact, sports facilities or sites not only produce beneficial cultural benefits, also brings objective economic benefits for sports venues.

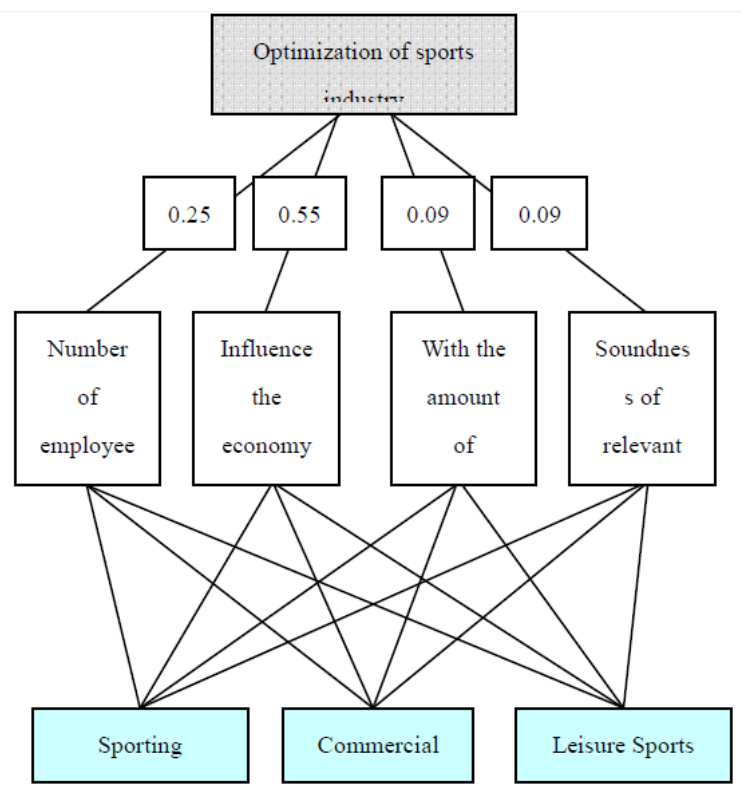

Figure 1. The structure of hierarchy model

The Multi-factor Analysis. Development is to make the hidden and not understood revealed, technology development is the use of existing knowledge gained from research and practical experience, or from an external introduction of technology, to produce new products, equipment, a new process and system for substantial improvement. Sports industry technology development is the use of new technology for production of new sports product, set up new process and system of work. Sports industry technology development policy is to use the technology for production of new sports product, set up new technology and the floorboard of the work system and policy. Is the purpose of the sports 
industry technical guide and promote the sports industry technology progress. Technology can not only save raw materials, capital and labor inputs, also can bring the transformation and upgrading of industrial structure directly. As a result, the sports industry technology is the necessary link of applying scientific research to production, the significant effect on the development of the sports industry. To sum up, our country's sports industry technology development policy mainly includes the development of sports intangible assets, the development and utilization of sports venues of aspects. Market development in the sports intangible assets in our country existing in the operation and protection of all sorts of problems, reflected in the law the first prominent problem is the lack of legal basis, and cross protection law and don't apply, can't adapt to the objective need of development of sports intangible assets. Small number of sports laws and regulations, the existing system mainly focus on the sports administrative management and organize all kinds of sports competition, facing the social exercise industry administrative regulation and control function of few sports legislation, to guide sports industry, sports market regulation laws, rarely sports legislation concerning intangible assets is not only far from system, in general is very lack.

Applications of the Model and Summary. In view of the situation of the sports industry development, the influence factors of the sports industry structure optimization should include supply structure, demand structure, science and technology, and international economic relations in four aspects. (1) Structure of sports consumption is in proportion to the various needs of the sports society, including social sports consumption level and structure, the level and structure of the demand of social sports. (2) Supply structure of sports resources are natural resources, labor resources and the status of sports social resources and relative prices. Natural resources are engaged in sports industry the necessary environment, site and material resources. (3) The level of sports science and technology refers to the ability of sports science and technology, science and technology innovation elements. Including sports management technology, the skill tactics of sports performance, sports supplies manufacturing technology of science and technology level. (4) International sports economic relations is to point to the sports industry in international relations, including sporting goods import and export trade, the flow of the sports events of international promotion, athletes, etc.

\section{Conclusion and Further Schedule}

Economic development is inevitably accompanied by transformation and upgrading of industrial structure, a new economic development with the new industrial structure. As a sunrise industry, sports industry has made great progress in our country. Sports industry technology policy, the policy enforcement mechanism of the sports industry is the key link, is also to ensure that the first link of the effective implementation of the sports industry policy. Since reform and opening-up, our country sports industry technology policy has experienced from scratch, from simple to rich, from affiliated to the evolution of specialization. But overall, the number of specialized sports industry technology policy of China, at present our country sports industry technology policy is limited to the sports industry technical standards, technical development, technical regulation, technical plan and so on several aspects, and in many other sports industry technical level is still blank. Rapid healthy and orderly development of the sports industry depend on perfect policy support, only have policies in place, the development of our country sports industry to achieve real success. In conclusion, our proposed model could enhance the management our sport industry in our country. In the future, we plan to conduct more related literature review to modify our current methodology.

\section{References}

[1] Volek, J. S., Noakes, T., Phinney, S. D., Volek, J. S., \& Noakes, T. (2015). Rethinking fat as a fuel for endurance exercise.. European Journal of Sport Science, 15, 1, 13-20. 
[2] JD, B., JA, H., \& JP., M. (2015). Carbohydrate availability and exercise training adaptation: too much of a good thing?. European Journal of Sport Science, 15, 1, 3-12.

[3] Masschelein, E., Thomis, M., Thienen, R. V., \& Hespel, P. (2015). High twin resemblance for sensitivity to hypoxia. Medicine \& Science in Sports \& Exercise, 47, Issue.

[4] Changqiu, L., Jing, L., \& Institute, L. (2014). On legislative protection of china's sport industry. Journal of Chengdu University of Technology(Social Sciences).

[5] B. Evans, M., \& A. Eys, M. (2015). Collective goals and shared tasks: interdependence structure and perceptions of individual sport team environments. Scandinavian Journal of Medicine \& Science in Sports, 25, 1, e139-e148.

[6] (Vana) Hutter, R. I., Oldenhof-Veldman, T., \& Oudejans, R. R. D. (2015). What trainee sport psychologists want to learn in supervision. Psychology of Sport and Exercise, 16, 101-109.

[7] SR, G. (2015). In search of lost time: when people undertake a new exercise program, where does the time come from? a randomized controlled trial. J Sci Med Sport, 18, 43-48.

[8] Mi-lin, C. (2014). Theory positioning and development research of inner mongolia minority sports cultural industry. Bulletin of Sport Science \& Technology.

[9] Smith, B., Lord, J., \& Tryce, S. (2015). Marginalized morality: making sense of questionable sport fan behaviors. Ideas in Marketing: Finding the New and Polishing the Old.

[10]DR, C., \& AK, B. (2015). Effects of exercise in the cold on ghrelin, pyy and food intake in overweight adults. Medicine and Science in Sports and Exercise. 